\title{
Invasive mucinous adenocarcinoma of the lung presenting as a large, thin-walled cyst: A case report and literature review
}

\author{
KEITA MASUZAWA ${ }^{1,2}$, NAOTO MINEMATSU ${ }^{1}$, MAMORU SASAKI ${ }^{1}$, \\ KAZUMA OHSAWA ${ }^{1}$, TATSUYA YAMAMOTO ${ }^{3}$, ARIFUMI IWAMARU ${ }^{3}$, \\ KENTARO OGATA $^{4}$, TOMOKO BETSUYAKU ${ }^{2}$ and MAROHITO MURAKAMI ${ }^{1}$ \\ ${ }^{1}$ Department of Medicine, Hino Municipal Hospital, Hino, Tokyo 191-0062; ${ }^{2}$ Division of Pulmonary Medicine, \\ Department of Medicine, Keio University School of Medicine, Tokyo 160-8582; ${ }^{3}$ Department of Surgery \\ and ${ }^{4}$ Division of Pathology, Federation of National Public Service Personnel Mutual Aid Associations, \\ Tachikawa Hospital, Tachikawa, Tokyo 190-8531, Japan
}

Received October 7, 2016; Accepted November 29, 2016

DOI: $10.3892 / \mathrm{mco} .2017 .1143$

\begin{abstract}
Invasive mucinous adenocarcinoma (IMA), formerly referred to as mucinous bronchioloalveolar carcinoma, is a rare variant form of invasive adenocarcinoma and is radiologically characterized by dense pneumonic consolidation, ground-glass opacity and nodules. By contrast, large, thin-walled cysts are rare. We herein report the case of a 75-year-old man with IMA presenting as a large, irregularly shaped cystic lesion. The histological diagnosis was based on specimens obtained during a bronchoscopy. The patient underwent lobectomy followed by anticancer chemotherapy for residual intrapulmonary metastases. Of note, the small metastatic nodules transformed into cystic lesions with thin walls and fused, forming a large, multiloculated cystic lesion. Typical pneumonic consolidation appeared in the pericystic parenchyma later during the clinical course. The available literature on this rare radiological manifestation was also reviewed and discussed. Clinicians should be aware of thin-walled cystic lesions as they may be an unusual radiological finding in IMA.
\end{abstract}

\section{Introduction}

Invasive mucinous adenocarcinoma (IMA), formerly referred to as mucinous bronchioloalveolar carcinoma, is distinct from non-mucinous adenocarcinoma and has been re-classified as a variant of invasive adenocarcinoma in the International

Correspondence to: Dr Naoto Minematsu, Department of Medicine, Hino Municipal Hospital, 4-3-1 Tamadaira, Hino, Tokyo 191-0062, Japan

E-mail: n.minematsu@hinohosp.jp

Abbreviations: IMA, invasive mucinous adenocarcinoma; CT, computed tomography

Key words: computed tomography, consolidation, cyst, invasive mucinous adenocarcinoma, lung cancer, check-bulb
Association for the Study of Lung Cancer/American Thoracic Society/European Respiratory Society lung adenocarcinoma classification system, due to its distinct clinical, radiological and pathological characteristics, as well as its distinct genetic background (frequent KRAS mutations) (1). The typical computed tomography (CT) findings in IMA include pneumonic consolidation, ground-glass opacity and nodules; by contrast, cystic lesions are rare. We herein describe a rare case of IMA presenting as a large cystic lesion.

\section{Case report}

A 75-year-old man was admitted to the Hino Municipal Hospital due to a productive cough and mucous sputum lasting for 6 months. The patient had no previous illness or history of cigarette smoking. A chest radiograph obtained on admission revealed infiltration in the lower lobe of the right lung. A chest CT scan revealed an irregularly shaped cystic lesion comprising thin walls in the lower lobe of the right lung ( $9 \mathrm{~cm}$ in maximum diameter) and a mixed, dense and ground-glass opacity occupying a portion of the pericystic parenchyma (Fig. 1A, C and E). The tissue specimens obtained during bronchoscopy revealed non-specific inflammatory findings, without any neoplasm or vasculitis. The tissue culture was positive for Streptococcus anginosus. As treatment with antibiotics was ineffective, the CT scan was repeated one and a half months later, showing a rapid increase in the size of the cyst and progression of the parenchymal opacity in the lower lobe of the patient's right lung (Fig. 1B, D and F). In addition, centriacinar small nodules, some of which were cystic, appeared in the right middle and left upper lobes. The second-chance bronchoscopy revealed an atypical epithelium with abundant cytoplasmic mucin in the lung specimen obtained from the right lower lobe. The patient was diagnosed with clinical stage IV (T4N0M1a) IMA of the lung and was transferred to the Tachikawa Hospital to undergo right lower lobectomy prior to anticancer chemotherapy, due to major concerns of complications, such as infection, hemorrhage, or rupture of the large cyst. The macroscopic findings of the resected right lower lobe included 
a sizeable cystic lesion (9x6x $2 \mathrm{~cm})$ and a white-colored solid nodule adjacent to the cyst (Fig. 2A). Microscopically, the large cystic space, situated just beneath the fibrous thickened visceral pleura, was lined by non-neoplastic bronchial epithelial cells on the pleural side, and it directly faced the pulmonary parenchyma with carcinoma invasion on the other side. In the pericystic parenchyma, atypical columnar epithelium with intracytoplasmic mucin proliferated chiefly in a lepidic growth pattern, occasionally invading the interstitium (Fig. 2B). In addition, emphysema-like airspace enlargement was observed at the opening portion of the bronchiole, with mucinous material filling the conductive airways in a portion of the carcinoma-invading areas (Fig. 2C). Tissue necrosis was not evident in the pericystic area or inside the cyst.

Following thoracic surgery, the patient was readmitted to Hino Municipal Hospital for further treatment. The timeline of the anticancer chemotherapy and the CT scans are shown in Fig. 3. As the cancer lesion contained little solid material at an earlier time point, the response to each chemotherapy regimen could not be determined. The chemotherapy regimen, comprising carboplatin and pemetrexed, was initiated 1 month after the surgery, and bevacizumab was added from the third cycle onwards. Following completion of 4 cycles of this regimen, the overall cyst size was not affected, but the cyst wall was found to be thinner at 3 months (Fig. 3). Continuous maintenance therapy with pemetrexed and bevacizumab was conducted until disease progression, which occurred after 7 cycles of the regimen, with enlargement of the pre-existing cystic lesions and the appearance of new lesions after 9 months (Fig. 3). The right-sided pleural effusion also increased (not shown), and the presence of adenocarcinoma cells was cytologically confirmed. Second- and third-line chemotherapy were sequentially administered using docetaxel and gemcitabine for 3 and 6 cycles, respectively. Chemotherapy with gemcitabine achieved stable disease for 3 months, but the cyst gradually increased in size and, interestingly, parenchymal opacity appeared in the area surrounding the cyst at 17 months (Fig. 3). Thereafter, the opacity expanded rapidly over 19 months, despite continued administration of vinorelbine (Fig. 3). The radiological changes observed on CT scans between 17 and 19 months resembled what had been initially observed 2 months prior to diagnosis (Fig. 1), suggesting that the primary lesion developed through a similar formative process. The anticancer chemotherapy ceased at 19 months. The lung infiltration had significantly worsened at 22 months (Fig. 3) and the patient succumbed to respiratory failure 2 months later.

\section{Discussion}

IMA is a rare variant of invasive adenocarcinoma, accounting for 2.2-3.9\% of resected adenocarcinoma cases (2-4). A pictorial review of IMA elucidated the typical CT findings, such as consolidation, ground-glass opacity and nodules (5-8). The bubble-like lucency of pseudocavitation formation in the consolidation or nodule was also a major finding, which was observed in 40-78\% of IMA cases (5-8). By contrast, a thin-walled cystic lesion, particularly a large cyst, is rare. In the present case, the initial CT findings demonstrated a mixture of two major components: An irregular-shaped large cystic lesion

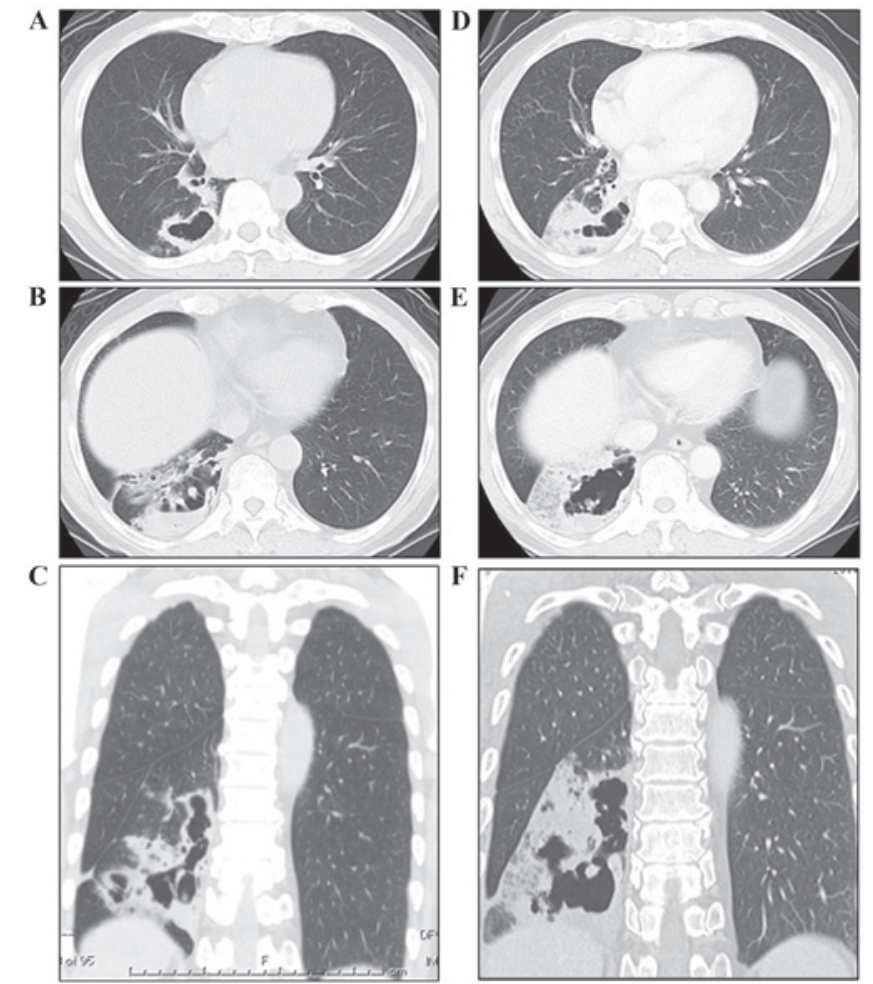

Figure 1. A chest computed tomography scan on admission (A, C and E) revealed an irregularly shaped cystic lesion with thin walls in the lower lobe of the right lung, and a mixed dense and ground-glass opacity was observed in a portion of the pericystic parenchyma. (B, D and F) One and a half months later, the cyst had enlarged and the surrounding opacity had expanded.

with thin walls, and a parenchymal opacity next to the cyst. It was unclear at diagnosis whether the cyst had developed primarily or formed secondarily in the pre-existing consolidation; however, the longitudinal CT observations throughout the entire course of the disease strongly suggested that the cystic lesion was the primary lesion.

A thin-walled cyst in the lungs is generally associated with benign disease, and it may delay the diagnosis of cancer $(9,10)$. Guo et al reported 15 cases of lung cancer presenting as a thin-walled cyst and reviewed the literature describing similar cases over the last two decades (11); they found adenocarcinoma to be the most common histological type (11 of 15 original cases and 11 of 19 reviewed cases) in a study including two cases of IMA (12). Prichard et al reported two original cases of IMA with a thin-walled cavity and found that none of the 10 previously reported cases of cystic lung cancer was histologically diagnosed as IMA in a review of the literature between 1947 and 1979 (12). Taken together, these studies suggest that cystic lesions are a rare radiological finding as a primary lesion in IMA.

We comprehensively reviewed the literature from another angle to identify the cases of IMA presenting as a large-size cyst or cavity ( $>5 \mathrm{~cm}$ in maximum diameter). A search was conducted through PubMed and the Ichu-shi website (Japanese database) and a total of 5 cases were identified, which are summarized in Table I. The ages of the patients ranged between 28 and 82 years, and the genders were equally distributed. All the subjects except 1 were never-smokers. The 
Table I. Invasive mucinous adenocarcinoma presenting as large cysts or cavities.

\begin{tabular}{|c|c|c|c|c|c|c|c|}
\hline $\begin{array}{l}\text { Age, } \\
\text { years }\end{array}$ & Gender & $\begin{array}{l}\text { Smoking } \\
\text { status }\end{array}$ & $\begin{array}{l}\text { Cavity size, } \\
\mathrm{cm} \text { (location) }\end{array}$ & $\begin{array}{l}\text { Radiological } \\
\text { description }\end{array}$ & Treatment & Mechanism & Refs. \\
\hline 41 & $\mathrm{~F}$ & Never & 6 (LLL) & $\begin{array}{l}\text { Solitary thin-walled cyst } \\
\text { Adjacent ill-defined mass }\end{array}$ & $\begin{array}{l}\text { Pneumonectomy } \\
\text { (recurrence } \rightarrow \mathrm{BSC} \text { ) }\end{array}$ & ND & $(12)$ \\
\hline 28 & M & Current & 11 (RLL) & Solitary thin-walled cavity & Lobectomy & ND & (13) \\
\hline 82 & M & Never & 10 (RLL) & $\begin{array}{l}\text { Mass lesion with thick-walled cavity } \\
\text { Thin-walled cystic cavity (metastases) }\end{array}$ & $\begin{array}{l}\text { Lobectomy } \\
\text { (recurrence } \rightarrow \mathrm{BSC} \text { ) }\end{array}$ & $\begin{array}{l}\text { Check-bulb } \\
\text { Necrosis }\end{array}$ & (14) \\
\hline 68 & $\mathrm{~F}$ & Never & 7 (RLL) & $\begin{array}{l}\text { Cavity surrounded by an } \\
\text { irregular wall }\end{array}$ & Lobectomy & $\begin{array}{l}\text { Neutrophilic } \\
\text { infiltrate }\end{array}$ & $(15)$ \\
\hline 51 & $\mathrm{~F}$ & Never & 6.5 (RLL) & Solitary thin-walled cavity & Lobectomy & Check-bulb & $(16)$ \\
\hline 75 & M & Never & 9 (RLL) & $\begin{array}{l}\text { Solitary thin-walled large } \\
\text { cyst with opacity } \\
\text { Thin-walled multiloculated } \\
\text { cyst (metastases) }\end{array}$ & $\begin{array}{l}\text { Lobectomy } \\
\text { Chemotherapy }\end{array}$ & Check-bulb & $\begin{array}{l}\text { Present } \\
\text { case }\end{array}$ \\
\hline
\end{tabular}

M, male; F, female; LLL, left lower lobe; RLL, right lower lobe; BSC, best supportive care; ND, not determined.
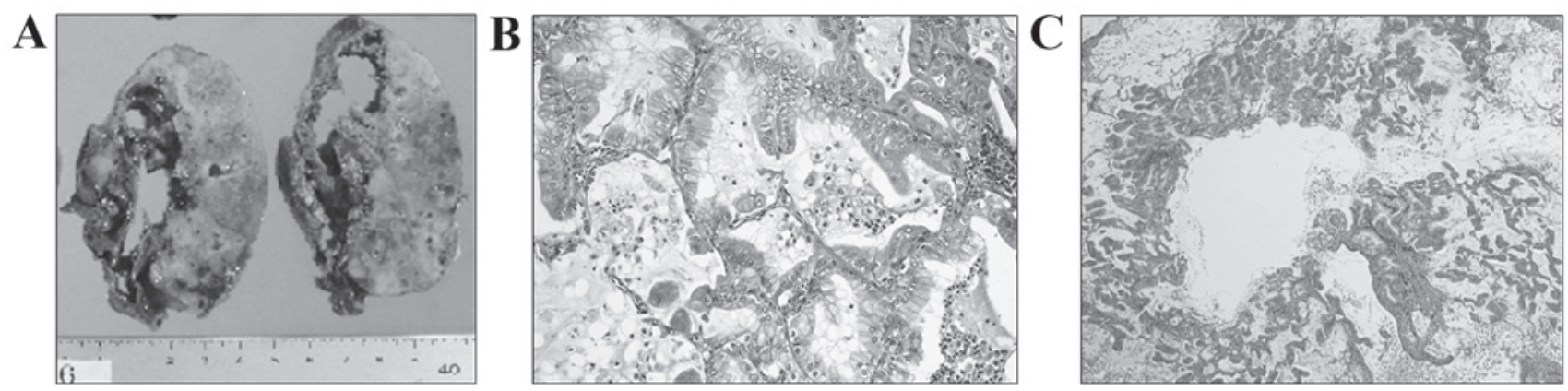

Figure 2. Macroscopic and microscopic findings of the resected lower lobe of the right lung. (A) On gross examination, a sizeable cystic lesion and a white-colored solid area adjacent to the cyst were observed. (B) Atypical mucinous columnar epithelium proliferating in a lepidic pattern in the pericystic area (original magnification, x100). (C) Emphysema-like airspace enlargement was observed at the opening portion of the bronchiole. The conductive bronchiole was filled with mucinous material (original magnification, $\mathrm{x} 40$ ).

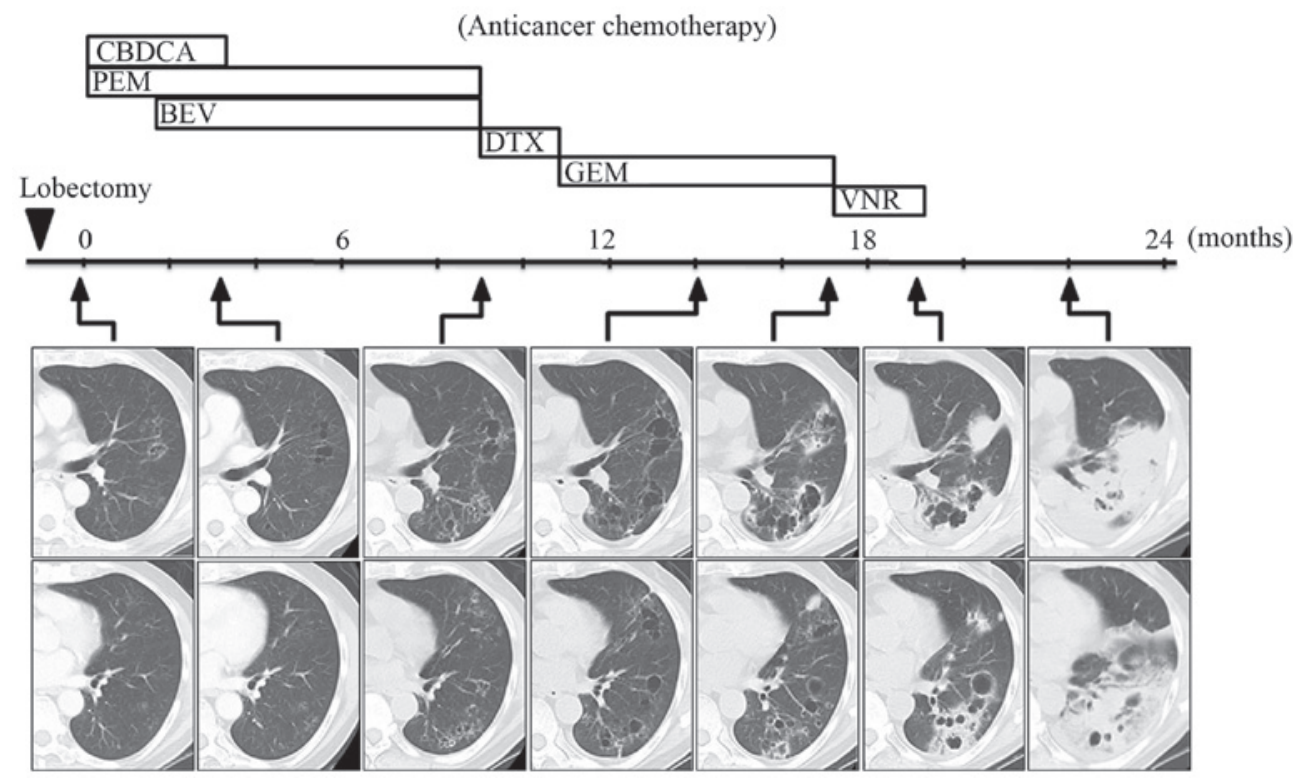

Figure 3. Clinical course and computed tomography findings after surgery. Chest computed tomography scans revealed the transbronchial metastases originally observed as small nodules enlarged and fused to form a multiloculated cyst without parenchymal opacity between 0 and 17 months. An enlarged cyst was ultimately accompanied by surrounding consolidation from 19 months onwards. CBDCA, carboplatin; PEM, pemetrexed; BEV, bevacizumab; DTX, docetaxel; GEM, gemcitabine; VNR, vinorelbine. 
primary lesions had cysts or cavities of $6-11 \mathrm{~cm}$ in maximum diameter and were predominantly located in the right lower lobe (5 of 6 cases). In 1 case, the primary lesion was in the left lower lobe. The lower lobe predominance was not previously observed in the review series of all IMA cases (17 of 36 cases) (5), or of lung cancers (regardless of the histological type) presenting as thin-walled cysts (6 of 15 cases) (11). By contrast, Manning et al reported a trend toward lower lobe predominance only in cases of IMA with solitary nodules (4 of 5 cases) (17). The cyst or cavity was described as 'thin-walled' in the primary lesion or the metastases in the majority of the cases (5 of 6 cases). The patients underwent surgical resection in all cases, and lobectomy was selected in 5 cases. Surgical resection was not curative in the present case; similarly, postoperative recurrence was also observed in two previous studies $(12,14)$. Of note, the patient described herein, as well as one of the two previously described patient (14), exhibited similar radiological changes on postoperative CT scans: i) The primary lesion was a large cystic lesion with peripheral opacity in the right lower lobe; ii) the transbronchial metastases were originally observed as small nodules, which enlarged and transformed into a multiloculated large cyst with thin walls; and iii) peripheral opacity was not observed until late in the clinical course.

Several mechanisms through which lung cancer forms a cavity or cyst have been proposed, such as ischemic tumor necrosis, check-bulb, or destruction of alveoli by a direct invasion, proteolysis, or excessive mucus retention. As IMA is generally considered to be less invasive and exhibits reduced necrotic tendency, the check-bulb mechanism is the most likely explanation of the formative process of the thin-walled cyst. As shown in Table I, the check-bulb mechanism was hypothesized to underlie cyst formation in 3 of the 4 cases, although necrosis and neutrophil infiltration were also suspected. In the present case, the check-bulb mechanism was indirectly supported by the histological findings of emphysema-like airspace enlargement and by the presence of an intraluminal mucous plug in the conductive airway. In the present case, as well as in another report (14), the air-filled cyst increased in size and its walls appeared thinner on postoperative CT scans, strongly suggesting the check-bulb mechanism. A recent study by Nakamura et al suggested a pivotal role of mucus retention in cavity formation in lung adenocarcinoma (18); however, cases of non-mucinous lung adenocarcinoma were also reported to display thin-walled large cysts $(11,19,20)$.

The explanation as to why the parenchymal opacity rapidly appeared late in the clinical course also remains unknown. Two possible explanations include accelerated tumor growth caused by a decreased effectiveness of the antitumor chemotherapy, or transformation of the tumor to another histological type. As discussed above, similar radiological changes were also observed in patients with IMA receiving only supportive care (14). In addition, the pathological findings observed in the pericystic lesion in our case showed a typical histology for IMA, growing in a lepidic pattern without transformation to another histological type.

In summary, we presented a rare case of IMA presenting as a large cyst with pericystic consolidation. This case was not unique, but it revealed the formative process of these rare radiological findings. Clinicians should be aware of thin-walled cystic lesions as they may represent an unusual radiological manifestation of IMA.

\section{Acknowledgements}

The authors would like to thank Editage (www.editage.jp) for the English language editing.

\section{References}

1. Travis WD, Brambilla E, Noguchi M, Nicholson AG, Geisinger KR, Yatabe Y, Beer DG, Powell CA, Riely GJ, Van Schil PE, et al: International association for the study of lung cancer/american thoracic society/european respiratory society international multidisciplinary classification of lung adenocarcinoma. J Thorac Oncol 6: 244-285, 2011.

2. Yoshizawa A, Sumiyoshi S, Sonobe M, Kobayashi M, Fujimoto M, Kawakami F, Tsuruyama T, Travis WD, Date H and Haga H: Validation of the IASLC/ATS/ERS lung adenocarcinoma classification for prognosis and association with EGFR and KRAS gene mutations: Analysis of 440 Japanese patients. J Thorac Oncol 8: 52-61, 2013.

3. Yanagawa N, Shiono S, Abiko M, Ogata SY, Sato T and Tamura G: The correlation of the international association for the study of lung cancer (IASLC)/American Thoracic Society (ATS)/European Respiratory Society (ERS) classification with prognosis and EGFR mutation in lung adenocarcinoma. Ann Thorac Surg 98: 453-458, 2014.

4. Mansuet-Lupo A, Bobbio A, Blons H, Becht E, Ouakrim H, Didelot A, Charpentier MC, Bain S, Marmey B, Bonjour P, et al: The new histologic classification of lung primary adenocarcinoma subtypes is a reliable prognostic marker and identifies tumors with different mutation status: The experience of a French cohort. Chest 146: 633-643, 2014.

5. Akira M, Atagi S, Kawahara M, Iuchi K and Johkoh T: High-resolution CT findings of diffuse bronchioloalveolar carcinoma in 38 patients. AJR Am J Roentgenol 173: 1623-1629, 1999.

6. Aquino SL, Chiles C and Halford P: Distinction of consolidative bronchioloalveolar carcinoma from pneumonia: Do CT criteria work? AJR Am J Roentgenol 171: 359-363, 1998.

7. Patsios D, Roberts HC, Paul NS, Chung T, Herman SJ, Pereira A and Weisbrod G: Pictorial review of the many faces of bronchioloalveolar cell carcinoma. Br J Radiol 80: 1015-1023, 2007.

8. Kim TH, Kim SJ, Ryu YH, Chung SY, Seo JS, Kim YJ, Choi BW, Lee SH and Cho SH: Differential CT features of infectious pneumonia versus bronchioloalveolar carcinoma (BAC) mimicking pneumonia. Eur Radiol 16: 1763-1768, 2006.

9. Wigh R and Gilmore FR: Solitary pulmonary necrosis; a comparison of neoplastic and inflammatory conditions. Radiology 56: 708-717, 1951.

10. Woodring JH, Fried AM and Chuang VP: Solitary cavities of the lung: Diagnostic implications of cavity wall thickness. AJR Am J Roentgenol 135: 1269-1271, 1980.

11. Guo J, Liang C, Sun Y, Zhou N, Liu Y and Chu X: Lung cancer presenting as thin-walled cysts: An analysis of 15 cases and review of literature. Asia Pac J Clin Oncol 12: e105-e112, 2016.

12. Prichard MG, Brown PJ and Sterrett GF: Bronchioloalveolar carcinoma arising in longstanding lung cysts. Thorax 39: 545-549, 1984.

13. De Jong PM, Busscher DL and Bakker W: Bronchioloalveolar carcinoma presenting as a thin walled cavity in a young man. Thorax 44: 230-231, 1989.

14. Isobe $\mathrm{K}$, Hata $\mathrm{Y}$, Iwata M, Ishida F, Kaburaki K, Gocho K, Kobayashi M, Sakaguchi S, Satou D, Sano G, et al: An autopsied case of mucinous bronchioloalveolar carcinoma associated with multiple thin-walled cavities. Nihon Kokyuki Gakkai Zasshi 47: 512-517, 2009 (In Japanese).

15. Tekeuchi Y, Kuwahara O, Tani Y, Ohta M, Obunai S and Hanada M: A case of the bronchiolo-alveolar cell carcinoma presenting multiple cavities and synchronous gastric cancer. Jpn J Lung Cancer 32: 397-402, 1992.

16. Kataoka K, Nakamura I, Sumiyoshi H, Fujiwara1 T, Matsuura M and Seno N: A case of bronchioloalveolar carcinoma with a thin-walled cavity associated with high uptake of $18 \mathrm{~F}$-fluorodeoxyglucose on positron emission tomography. Jpn J Lung Cancer 48: 861-865, 2008. 
17. Manning JT Jr, Spjut HJ and Tschen JA: Bronchioloalveolar carcinoma: The significance of two histopathologic types. Cancer 54: 525-534, 1984.

18. Nakamura S: CT Findings of pneumonic adenocarcinoma: Comparison between invasive mucinous adenocarcinoma and nonmucinous adenocarcinoma. GJMR-D 14: Version 1.0, 2014.

19. Matsushima H, Oda T, Hasejima N, Kou E, Kadoyama C and Takezawa S: Pulmonary adenocarcinoma with multiloculated cystic change. Nihon Kokyuki Gakkai Zasshi 45: 556-559, 2007 (In Japanese).
20. Yoshida T, Harada T, Fuke S, Konishi J, Yamazaki K, Kaji M, Morikawa T, Ota S, Itoh T, Dosaka-Akita $\mathrm{H}$ and Nishimura M: Lung adenocarcinoma presenting with enlarged and multiloculated cystic lesions over 2 years. Respir Care 49: 1522-1524, 2004. 